\title{
Impact of Contracted Endodontic Access Cavity on Shaping Ability of Hyflex Electrical Discharge Machining Single File Using Cone Beam Computed Tomography: An Ex Vivo Study
}

\author{
Ahmed Bayoumi ${ }^{1 *(1)}$, Magdy Mohamed Aly ${ }^{2,3}$, Reham Hassan ${ }^{3,4}$ (D) \\ ${ }^{1}$ Department of Conservative Dentistry, Faculty of Dentistry, Alexandria University, Alexandria, Egypt; ${ }^{2}$ Department of \\ Endodontics, Faculty of Dentistry, Beni Suef University, Beni Suef, Egypt; ${ }^{3}$ Department of Endodontics, Faculty of Dentistry, \\ Minia University, Minya, Egypt; ${ }^{4}$ Department of Endodontics, Faculty of Dentistry, Egyptian Russian University, Badr City, Egypt
}

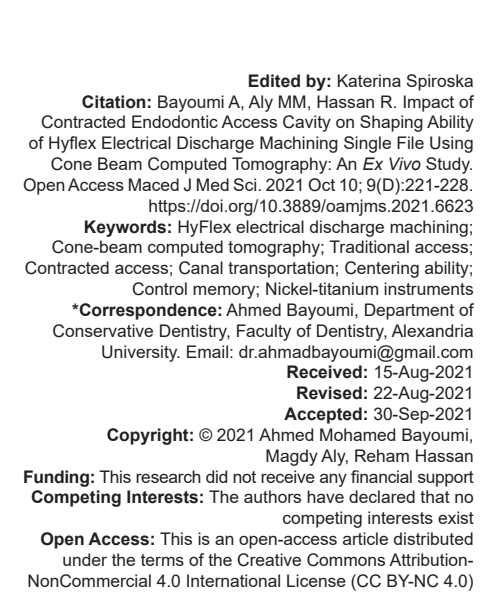

\begin{abstract}
AIM: The aim of the study was to evaluate and compare the effect of different access cavity designs, using conebeam computed tomography $(\mathrm{CBCT})$, on root canal transportation, and centralization performed on two rooted maxillary premolars.

METHODS: Twenty maxillary premolars were randomly divided into two groups. In Group 1, traditional endodontic cavities (TECs) were prepared. In Group 2, contracted endodontic cavities (CECs) were prepared. Mechanical preparation was done by HyFlex electrical discharge machining (EDM) single file in both groups. CBCT imaging was performed pre- and post-root canal preparation for calculations of root canal transportation and centering ability.

RESULTS: Data were analyzed using Mann-Whitney $U$ test and Kruskal-Wallis test. For transportation, teeth with CECs showed the statistically significantly highest median amount of transportation, while as for centering ability, results showed no significant difference between both groups.

CONCLUSION: Under the conditions of this study, HyFlex EDM prepared canals with different access cavity designs without significant shaping errors. TEC showed less transportation than CEC, while both TEC and CEC had no effect
\end{abstract} on the file centering ability.

\section{Introduction}

Endodontic access cavity is a crucial step to ensure that all root canals are properly cleaned, shaped, and filled [1] by enhancing both canal detection and instrumentation effectiveness through elimination of coronal interferences [2]. As an alternative to the traditional endodontic access cavities (TECs), minimally invasive endodontic cavities or contracted endodontic cavities (CECs) have been recently presented in the endodontic literature [3], [4], [5], stressing on the significance of maintaining the integrity of the tooth structure, and conserving the pericervical dentin. While contracted access cavities aims mainly to preserve tooth structure, however the limited accessibility and coronal interference may lead to endodontic instruments to function mostly on the root canal's internal surface, resulting in root canal transportation that negatively affects long-term prognosis due to excessive removal of dentin and straightening of the original root canal curvature [6], [7]. New generations of NiTi rotary instruments have recently been introduced, with higher flexibility and greater cutting efficiency. HyFlex electrical discharge machining (HFEDM) rotary Niti file system is submitted to controlled memory (CM) treatment, which has been shown to significantly increase flexibility and resistance to cyclic fatigue. HFEDM is currently the only instrument developed by electrical discharge machining (EDM), the design is distinguished by a variable cross section, shifting from a triangular cross section at the shaft side which provide more flexibility and fatigue resistance to rectangular at the tip (yielding higher torsional resistance) [8]. Despite the different instrument designs and metallurgical advancements, root canal preparation is negatively influenced by the anatomical variation of root canals [7].

The root form and canal anatomy of maxillary first premolars are highly variable. The most common anatomical features include two roots, narrow furcation entrances, deep mesial concavities and the presence of the palatal furcation groove of the buccal root, which is a developmental depression located at the palatal aspect of the buccal root [9]. Lack of knowledge about 
the extent and thickness of the dentin in this area might lead to excessive thinning of the dentinal wall during endodontic procedure [10].

The preservation of dentin with CECs preparation can be guided using cone beam computed tomography (CBCT) technology as pre-access analyses can provide information regarding the number root canals and their orientation within the tooth. It can also identify the presence of complex anatomy such as developmental anomalies, isthmuses, and the presence buccolingually broad canals, which if taken into consideration before the access preparation, would lead to increasing the precision of CECs preparation [11].

Therefore, the aim of the present study was to compare the effect of different access cavity designs on root canal transportation and instrument centralization performed on two rooted maxillary premolars using CBCT. The null hypothesis tested was that there would be no influence of the type of endodontic cavity on any of the outcomes investigated.

\section{Materials and Methods}

\section{Sample size calculation}

The sample size was calculated based on previous studies comparing TECs and CECs [12], [13], both with ten teeth per group. Accordingly, using alpha $(\alpha)$ level of 0.05 and study power $=80 \%$, the minimum estimated sample size was (10) per group giving a total of 20 samples.

\section{Sample selection and grouping}

After the approval of a local ethics committee of Faculty of Dentistry, Minia University, a total of 20 intact, mature human two-rooted maxillary premolars extracted for orthodontic or periodontal reasons with similar length and a degree of curvature ranging between $10^{\circ}$ and $24^{\circ}$ were selected and stored in $0.9 \%$ saline solution at $4^{\circ} \mathrm{C}$ until use[14]. Degree of curvature was measured using Schneider's technique [15] in which teeth were radiographed buccolingually, two lines were used to measure the angle of curvature, the first was drawn parallel to long axis of the canal, the second one was drawn from the apical foramen to intersect with the first at the point where the canal began to leave the long axis of the tooth, the acute angle formed was measured, and the angle of curvature was determined. Teeth that showed calcification, open apices, previous endodontic treatment teeth or resorption (internal or external resorption) after radiographic examination were excluded from the study. Group allocation was performed randomly into two groups ( $n=10$ per group) using a random group allocation online software (https:// www.ramdomizer.org) where only the buccal root was considered in the study. The two groups were allocated based on the type of endodontic access preparation; Group I: Traditional endodontic access design, and Group II: Contracted endodontic access design. All teeth were fixed by mounting them vertically halfway in transparent auto polymerizing acrylic resin (Acrostone, Dental and Medical Supplies, Cairo, Egypt) mixed according to the manufacturer's instructions, and then scanned by CBCT before instrumentation.

\section{Group I: TECs}

Endodonticaccesscavitiesweredrilled with highspeed diamond burs (BR-41 Round bur, Mani, Japan) followed by Endo Z drill (Dentsply Maillefer, Ballaigues, Switzerland) according to conventional access cavity principles described in the literature [16], [17]. The roof of the chamber was removed; the path to canal orifices was unimpeded and unobstructed, providing a straightline access (Figure 1).

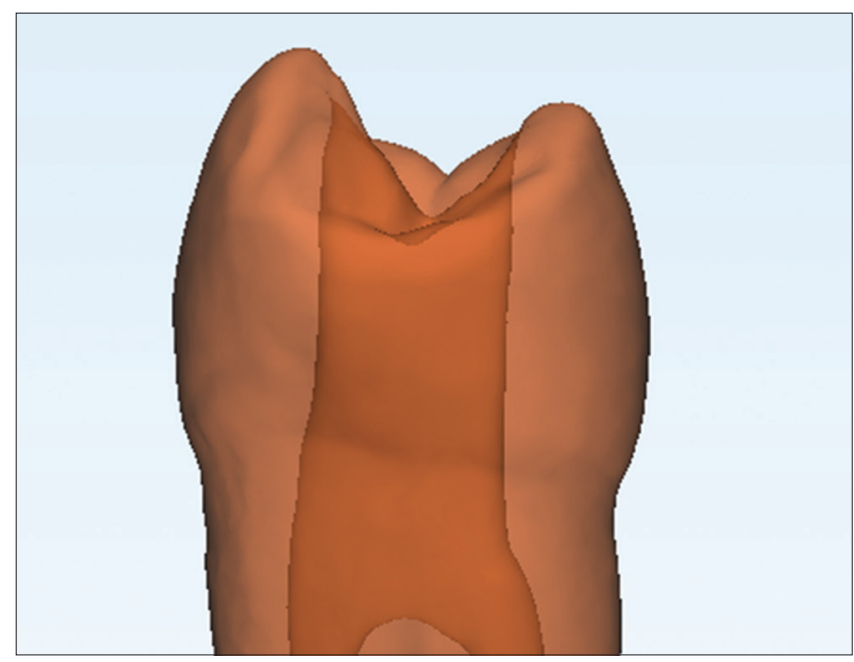

Figure 1: Traditional endodontics access

\section{Group II: CECs}

Endodontic access cavities were drilled with high-speed diamond burs (BR-41 Roundbur, Mani, Japan). The teeth were accessed at the central fossa with minimal extension enough to detect canal orifices, to preserve pericervical dentin as well as part of the chamber roof [18], [19] (Figure 2a and b).

\section{Root canal preparation}

The apical patency of all root canals was confirmed using a \#10 K-file (Dentsply Maillefer, Baillagues, Switzerland), Working length was determined using a \#10 K-file (Dentsply Maillefer, Baillagues, Switzerland), which was introduced into the root canal until it became visible at the apical foramen. Working length was set to $1 \mathrm{~mm}$ short of 


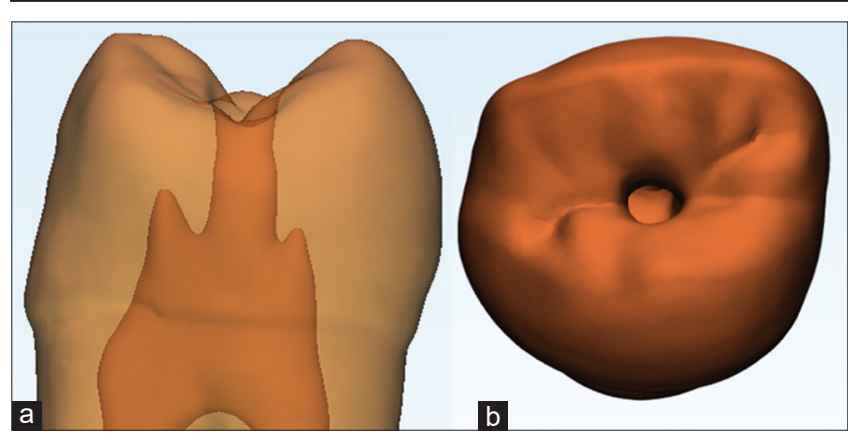

Figure 2: Contracted endodontics access, (a) proximal view, (b) occlusal view

the apex. 25/ HyFlex EDM one file system (Coltene, Whaledent, Cuyahoga Falls, OH, USA) was used for shaping the canals of both groups. All instruments were driven using the X-Smart Plus (Dentsply Maillefer, Baillagues, Switzerland). The files were operated at 400-rpm speed and torque of $2 \mathrm{Ncm}$. Each of the files was used to shape a maximum of four root canals, root canals were irrigated with $2 \mathrm{~mL} 5.25 \%$ sodium hypochlorite (CanalPro; Coltene/Whaledent, Allstetten, Switzerland) solution, $2 \mathrm{~mL}$ 17\% EDTA (CanalPro; Coltene/Whaledent, Allstetten, Switzerland) were used to remove the smear layer, followed by $2 \mathrm{~mL}$ saline and then $2 \mathrm{~mL} 5.25 \%$ sodium hypochlorite were used as a final irrigation and dried with paper points. A single experienced endodontist (A.B) performed all access cavities preparation and instrumentation to avoid inter-operator variability, all steps were done under magnification (4.3× magnification EyeMag Smart Loupes; Carl Zeiss Meditec; Jena, Germany).

\section{Image capture}

Root canal transportation and instrument centralization were measured both pre and post mechanical preparation at the level of $3 \mathrm{~mm}, 6 \mathrm{~mm}$, and $9 \mathrm{~mm}$ from the apex. The sagittal and coronal views were used to adjust the orientation of the measuring planes, while the measurements were carried out in the axial view. Navigation in the axial plane started at the most extreme point of the root apex and continued for $3 \mathrm{~mm}, 6 \mathrm{~mm}$, and $9 \mathrm{~mm}$. СВCT images were obtained using a Vatech Pax-i3D Green scanner (VATECH GREEN Inc., Hwaseong-si, Gyeonggi, Korea) with the following settings: Field of view of $50 \mathrm{~mm} \times$ $50 \mathrm{~mm}$, voxel of $0.080 \mathrm{~mm}$, tube voltage of $94 \mathrm{kVp}$, tube current of $10 \mathrm{~mA}$, and exposure time of $12.2 \mathrm{~s}$. Images were examined using the scanner's proprietary software (EZ3d-I, VATECH GREEN Inc., Hwaseong-si, Gyeonggi, Korea). All teeth were scanned using the same CBCT machine with the same exposure settings.

\section{Evaluation of canal transportation and centering ability}

The formula introduced by Gambill et al. [20] was used to measure the degree of canal transportation. ([x1-x2]-[y1-y2]), where $x 1$ and $x 2$ were the shortest pre-instrumenation and post-instrumentation mesial distance, respectively, $\mathrm{y} 1$ and $\mathrm{y} 2$ were the shortest pre-instrumentation and post-instrumentation distal distance, respectively. The result of " 0 " indicates no canal transportation and other than " 0 " means that transportation has occurred. The following formula was used for the calculation of centering ability, $(\mathrm{x} 1-\mathrm{x} 2) /(\mathrm{y} 1-$ $y 2)$ or $(y 1-y 2) /(x 1-x 2)$. If the numbers are not equal, the lower figure was considered as the numerator and a result of "1" indicates perfect centering (Figure 3). A second examiner (R.H) who was blinded to all experimental groups performed the measurements (Figure 4). Each specimen had two measurements for reliability.

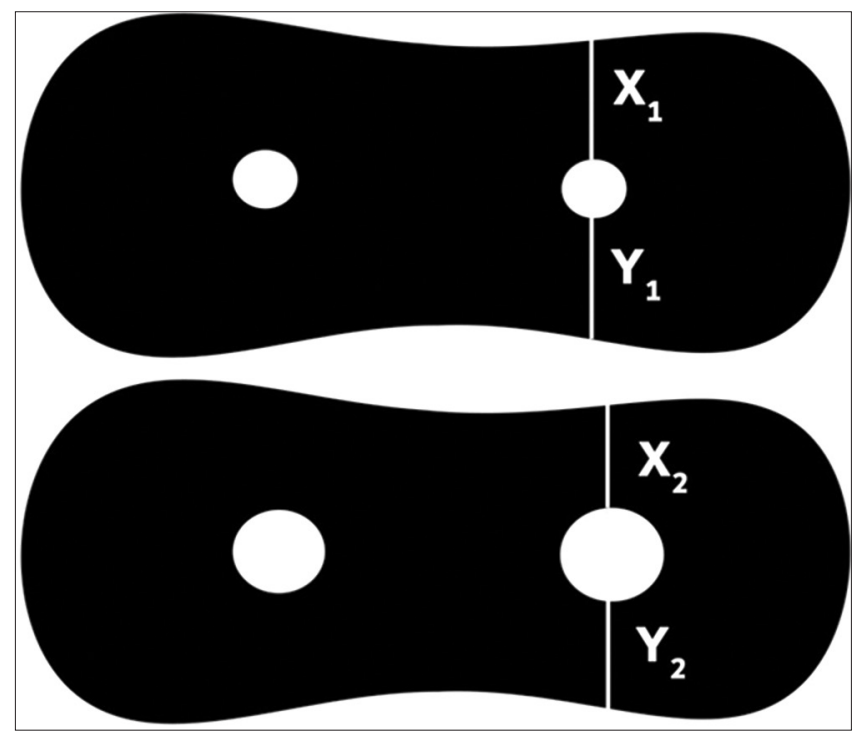

Figure 3: Pre-instrumentation and post-instrumentation diagram with markings showing points of measurements used for determining canal transportation and centering ratio
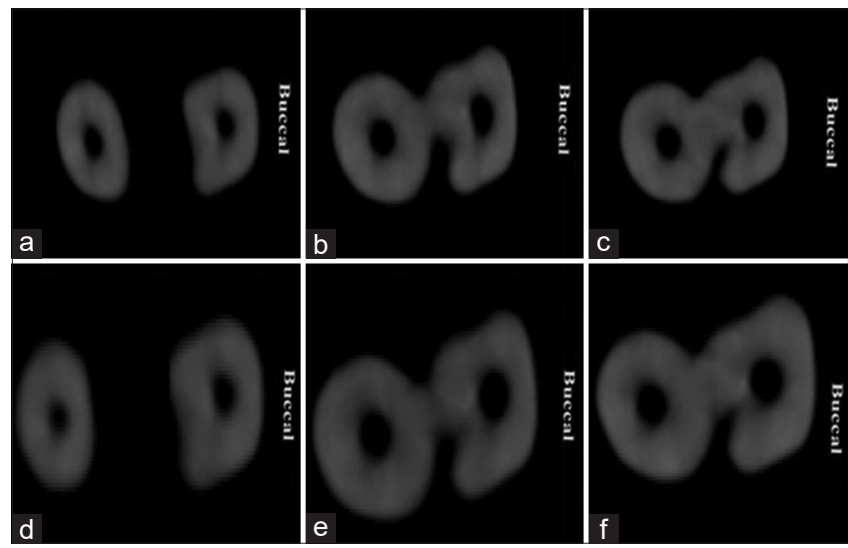

Figure 4: Representative cone-beam computed tomography images in axial view for traditional endodontic access cavity group used to evaluate transportation and centering ability, (a to c) before and ( $d$ to $f$ ) after instrumentation at $3 \mathrm{~mm}$ ( $a$ and $d), 6 \mathrm{~mm}$ ( $b$ and e), and $9 \mathrm{~mm}$ ( $c$ and $f)$

\section{Statistical analysis}

Data were explored for normality using Kolmogorov-Smirnov test and showed non-parametric 
distribution. Data were described using minimum, maximum, median, and inter-quartile. Comparisons were carried out between two studied independent notnormally distributed subgroups using Mann-Whitney U test and between more than two studied independent notnormally distributed subgroups using Kruskal-Wallis test. Post hoc pair-wise comparisons when Kruskal-Wallis test was significant were carried out using Dunn-Sidak test for multiple comparisons. An alpha level was set to $5 \%$ with a significance level of $95 \%$, and a beta error accepted up to $20 \%$ with a power of study of $80 \%$. Statistical analysis was performed with Statistical Package for the Social Science (SPSS) program for statistical analysis (IBM Corp. IBM SPSS Statistics for Windows, Version 21.0. Armonk, NY: IBM Corp.; Released 2012). Intraclass Correlation Coefficient (ICC) estimates and their 95\% confident intervals were calculated using SPSS statistical package version 23 (SPSS Inc, Chicago, IL) based on a meanrating $(\mathrm{k}=2)$, absolute-agreement, and 2-way mixedrandom model [21].

\section{Results}

During mechanical preparation, neither instrument fracture nor loss of working length was encountered in any of the teeth. A high degree of reliability was found between the two readings for transportation. The single ICC was 0.972 with a $95 \%$ confidence interval from 0.945 to $0.985\left(\mathrm{~F}_{(59,59)}=\right.$ $81.420, p<0.001$ ) (Table 1), and was 0.999 with a $95 \%$ confidence interval from 0.998 to $0.999\left(\mathrm{~F}_{(59,59)}=\right.$ 1725.500, $p<0.001$ ) for centering ability (Table 2).

\section{Transportation}

At $3 \mathrm{~mm}, 6 \mathrm{~mm}$, and $9 \mathrm{~mm}$ root level from the apex; there was statistically significant difference between the two endodontic cavity designs, MannWhitney comparisons between both cavity designs revealed that teeth with CECs showed the statistically significantly highest median (IQR) amount of transportation at all levels. For each cavity design; there was no statistically significant difference between amounts of transportation between $3 \mathrm{~mm}, 6 \mathrm{~mm}$, and $9 \mathrm{~mm}$ (Table 3).

As regarding the total amount of absolute transportation (median of the three root levels for each group); there was statistically significant difference between the two groups CECs showed the statistically significantly highest median amount of transportation $0.12(0.07-0.16)$ while TECs showed the lowest amount of transportation $0.05(0.03-0.06, p=0.000)$ (Table 4).

\section{Centering ability}

At $3 \mathrm{~mm}, 6 \mathrm{~mm}$, and $9 \mathrm{~mm}$ root level from the apex; there was no statistically significant difference between the two endodontic cavity designs. For each cavity designs; there was no statistically significant difference in term of centering ability between $3 \mathrm{~mm}$, $6 \mathrm{~mm}$, and $9 \mathrm{~mm}$ (Table 5). As regard the total amount of absolute centering ability (median of the three root levels for each group); there was no statistically significant difference between the two groups ( $p=$ 0.824) (Table 6).

\section{Discussion}

The emergence of minimally invasive dentistry [18], [19] has led to the modern concept of conservative endodontic access cavity; which targets the preservation of sound dentine by avoiding both complete de-roofing of the pulp chamber and avoiding over-flaring of canal orifices as well as avoiding aggressive dentine removal for shaping [20], especially around the pericervical dentin (located $4 \mathrm{~mm}$ above and below the crestal bone) where it acts as a buttress against structural flexure and ultimate fracture [22]. The leaning to cut smaller-sized access cavities was influenced by the use of illumination together with magnification, highly flexible instruments, and better imaging devices such as CBCT [11], while it is essential to shift the modern endodontic treatment toward a conservative ideology [23]; however, it is also necessary to

Table 1: ICC for transportation test

\begin{tabular}{|c|c|c|c|c|c|c|c|}
\hline \multirow[t]{2}{*}{ Measurments } & \multirow[t]{2}{*}{ Intraclass Correlationb } & \multicolumn{2}{|c|}{ 95\% Confidence Interval } & \multicolumn{4}{|c|}{ F Test with True Value 0} \\
\hline & & Lower Bound & Upper Bound & Value & df1 & df2 & Sig \\
\hline Single Measures & $0.972 a$ & 0.945 & 0.985 & 81.420 & 59 & 59 & 0.000 \\
\hline Average Measures & 0.986 & 0.972 & 0.992 & 81.420 & 59 & 59 & 0.000 \\
\hline
\end{tabular}

ICC: Intraclass Correlation Coefficient, Two-way random effects model where both people effects and measures effects are random. (a): The estimator is the same, whether the interaction effect is present or not. (b) Type A intraclass correlation coefficients using an absolute agreement definition.

Table 2: ICC for centering ability test

\begin{tabular}{|c|c|c|c|c|c|c|c|}
\hline \multirow[t]{2}{*}{ Measurments } & \multirow[t]{2}{*}{ Intraclass Correlation b } & \multicolumn{2}{|c|}{ 95\% Confidence Interval } & \multicolumn{4}{|c|}{ F Test with True Value 0} \\
\hline & & Lower Bound & Upper Bound & Value & df1 & df2 & Sig \\
\hline Single Measures & $0.999 a$ & 0.998 & 0.999 & 1725.500 & 59 & 59 & 0.000 \\
\hline Average Measures & 0.999 & 0.999 & 1.000 & 1725.500 & 59 & 59 & 0.000 \\
\hline
\end{tabular}

intraclass correlation coefficients using an absolute agreement definition. 
provide an adequate endodontic access to achieve optimal shaping as it is claimed that coronal interferences with CECs can increase the operative difficulties during canal instrumentation that may lead to root canal transportation.

Table 3: Median (IQR) and minimum-maximum values of buccal roots transportation $(\mathrm{mm})$ at different root levels for both endodontic cavity designs

\begin{tabular}{|c|c|c|c|}
\hline Root levels & TECs $(n=10)$ & $\operatorname{CECs}(n=10)$ & $\begin{array}{l}\text { Test of significance } \\
P \text { value }\end{array}$ \\
\hline \multicolumn{4}{|l|}{$3 \mathrm{~mm}$} \\
\hline Min-Max & $0.01-0.09$ & $0.01-0.41$ & \multirow{2}{*}{$\begin{array}{l}Z(M W)=2.138 \\
p=0.033^{*}\end{array}$} \\
\hline Median (IQR) & $0.05(0.03-0.05)$ & $0.16(0.06-0.16)$ & \\
\hline \multicolumn{4}{|l|}{$6 \mathrm{~mm}$} \\
\hline Min-Max & $0.03-0.13$ & $0.08-0.27$ & \multirow{2}{*}{$\begin{array}{l}Z(M W)=2.901 \\
p=0.004^{*}\end{array}$} \\
\hline Median (IQR) & $0.05(0.03-0.06)$ & $0.12(0.12-0.15)$ & \\
\hline \multicolumn{4}{|l|}{$9 \mathrm{~mm}$} \\
\hline Min-Max & $0.00-0.15$ & $0.02-0.31$ & \multirow{4}{*}{$\begin{array}{l}Z(M W)=1.978 \\
p=0.048^{*}\end{array}$} \\
\hline Median (IQR) & $0.05(0.00-0.06)$ & $0.09(0.07-0.12)$ & \\
\hline Test of significance & $\chi_{(\mathrm{df}=2)}^{2}=0.623$ & $\chi_{(\mathrm{df}=2)}^{2}=0.790$ & \\
\hline$P$ value & $p=0.732$ NS & $p=0.674 N S$ & \\
\hline
\end{tabular}

Maxillary premolars were selected as several studies have reported that the presence of grooves on the furcation aspects of the buccal roots of maxillary premolars varied between $62 \%$ and $100 \%$ based on different evaluation methods [10], [24]. Excessive removal of dentin with thin canal walls present in maxillary premolars may lead to unnecessary weakening of the tooth and subject it to higher risk for root fracture.

Table 4: Median (IQR) and minimum-maximum values of the entire buccal roots levels in term of transportation ( $\mathrm{mm}$ ) for both endodontic cavity designs

\begin{tabular}{|c|c|c|c|}
\hline $\begin{array}{l}\text { Min-Max, } \\
\text { Median } \\
\text { evaluation }\end{array}$ & TECs $(n=30)$ & CECs $(n=30)$ & $\begin{array}{l}\text { Test of significance, } \\
P \text { value }\end{array}$ \\
\hline Min-Max & $0.00-0.15$ & $0.01-0.41$ & $Z_{(\mathrm{MW})}=-4.059$ \\
\hline Median (IQR) & $0.05(0.03-0.06)$ & $0.12(0.07-0.16)$ & $p=0.000^{*}$ \\
\hline
\end{tabular}

Hence, in this study, we compared the shaping ability of one endodontic instrument with two different access cavity designs in the maxillary premolars using a well-established technique [25]. Two parameters were used in this comparison, canal transportation, and centering ability using CBCT scanning, which was used because it provides three-dimensional evaluation of changes of the root canal dentin thickness and volume before and after mechanical preparation in a precise and reproducible method [20], [26]. CBCT was used in the current study for radiographic analysis as it provides precise and reproducible calculations of root canal changes before and after instrumentation [27], [28], [29].

Table 5: Median (IQR) and minimum-maximum values of buccal roots in term of centering ability $(\mathrm{mm})$ at different root levels for both endodontic cavity designs

\begin{tabular}{|c|c|c|c|}
\hline Root levels & TECs $(n=10)$ & CECs $(n=10)$ & $\begin{array}{l}\text { Test of significance, } \\
P \text { value }\end{array}$ \\
\hline \multicolumn{4}{|l|}{$3 \mathrm{~mm}$} \\
\hline Min-Max & $0.25-2.50$ & $0.09-2.00$ & \multirow{2}{*}{$\begin{array}{l}Z_{(\mathrm{MW})}=1.216 \\
P=0.224 \mathrm{NS}\end{array}$} \\
\hline Median (IQR) & $1.06(0.55-1.08)$ & $0.83(0.50-0.83)$ & \\
\hline \multicolumn{4}{|l|}{$6 \mathrm{~mm}$} \\
\hline Min-Max & $0.19-5.33$ & $0.29-3.45$ & \multirow{2}{*}{$\begin{array}{l}Z_{(\mathrm{MW})}=0.000 \\
P=1.000 \mathrm{NS}\end{array}$} \\
\hline Median (IQR) & $1.44(0.57-1.75)$ & $1.40(0.43-2.33)$ & \\
\hline \multicolumn{4}{|l|}{$9 \mathrm{~mm}$} \\
\hline Min-Max & $0.33-3.00$ & $0.21-4.88$ & \multirow{3}{*}{$\begin{array}{l}Z_{(m w)}=0.607 \\
P=0.544 \mathrm{~ns}\end{array}$} \\
\hline Median (IQR) & $1.10(1.00-1.10)$ & $1.60(0.31-3.25)$ & \\
\hline $\begin{array}{l}\text { Test of significance, } \\
P \text { value }\end{array}$ & $\begin{array}{l}\chi_{(\mathrm{df}=2)}^{2}=0.909, \\
P=0.635 \mathrm{NS}\end{array}$ & $\begin{array}{l}\chi_{(\mathrm{df}=2)}^{2}=1.789, \\
P=0.409 \mathrm{NS}\end{array}$ & \\
\hline
\end{tabular}

While Micro-CT remains the golds standard and the reference tool for evaluating the shaping abilities of new NiTi files, since it enables the image to be acquired within the range of $5-50 \mathrm{~mm}$ voxel size, the small voxel size permits the assessment of accumulation of hard tissue debris, untouched root canal walls and the sum of dentin removed [30]. However, different methodologies have been recently employed. Bürklein et al. 2021 [31] compared the shaping ability of conventional austenite 55-NiTi alloy instruments F360, F6 SkyTaper (both Komet, Lemgo, Germany), and the heat-treated NiTi Jizai, Silk-Complex and Silk-Standard instruments (all Mani, Tochigi, Japan) using standardized radiographs. Arıcan-Öztürk et al. 2020 [32] used CBCT to compare the shaping abilities of the XP-endo Shaper and ProTaper Next systems. It worth mentioning that there was no significant difference between $76 \mathrm{~mm}$ voxel size at CBCT and $20 \mathrm{~mm}$ voxel size at micro-CT in the study of the tooth anatomy in endodontic therapies [33] using maxillary molars on the cadaver.

Table 6: Median (IQR) and minimum-maximum values of the entire buccal roots levels in term of centering ability $(\mathrm{mm})$ for both endodontic cavity designs

\begin{tabular}{|c|c|c|c|}
\hline $\begin{array}{l}\text { Min-Max, } \\
\text { Median } \\
\text { evaluation }\end{array}$ & TECs $(n=30)$ & CECs $(n=30)$ & $\begin{array}{l}\text { Test of significance, } \\
P \text { value }\end{array}$ \\
\hline Min-Max & $0.19-5.33$ & $0.09-4.88$ & $Z_{(M W)}=0.222$ \\
\hline Median (IQR) & $1.08(0.57-1.59)$ & $0.83(0.43-1.79)$ & $P=0.824 \mathrm{NS}$ \\
\hline
\end{tabular}
$\mathrm{n}$ : Number of specimens, Min-Max: Minimum - Maximum,
significant $(p<0.05)$, NS: Statistically not significant $(\mathrm{p}>0.05)$.

In this study, shaping outcomes after instrumentation with HyFlex EDM single file were analyzed. The main proposed benefits of the single endodontic file system are cost effectiveness, prevention of cross contamination, and decreased instrument fatigue with single use of the instrument. The tested hypothesis was rejected, as the transportation observed in the CEC group was statistically higher than that observed in the TEC group at each analyzed level. It has been suggested that $0.15 \mathrm{~mm}$ apical transportation is acceptable [33]; however, if apical transportation exceeds $0.3 \mathrm{~mm}$, it will have a negative impact on root canal filling [34]. In this study, although the median (IQR) of both groups was within the accepted limit, some specimens of the CECs particularly at the apical part of the canal exceeded this critical level, and the maximum value of $0.41 \mathrm{~mm}$ was considered not to be within the acceptable limit. This could be explained by the increased level of difficulty during instrumentation caused by coronal interferences and the absence of straight-line access that led to excessive instrument pressure against the outer aspect of the root canal curvature and to the increased number of pecking motions needed to reach the working length. Summing of canal transportation of the three root levels $(3 \mathrm{~mm}$, $6 \mathrm{~mm}$, and $9 \mathrm{~mm}$ ) of TEC group and comparing them to their correspondence in the CEC group showed significant difference with the better results achieved in TEC group. The result of the present study revealed that the type of access cavity influenced the shaping outcome in term of transportation and this result is in 
line with the findings of Alovisi et al. [35] where they demonstrated significantly more canal transportation in CECs when compared to TECs, even when using $\mathrm{CM}$ instruments. Similar results could be observed in a study by Rover et al. [36] where canal transportation was significantly higher for the CEC group in the palatal canal of upper molars at $7 \mathrm{~mm}$ from the apical end than TEC group even when using M-Wire NiTi technology, probably because of the straight-line access in the TEC group. Regardless of the NiTi file system used, studies have showed the negative influence of CECs on the original canal anatomy especially on mandibular molars [12], [13].

In the analysis of centering ability, no significant difference was seen between TECs and CECs at the three tested levels, the summing of the three root levels ( $3 \mathrm{~mm}, 6 \mathrm{~mm}$, and $9 \mathrm{~mm}$ ) of TEC group showed better results when compared to the summing of the three root levels ( $3 \mathrm{~mm}, 6 \mathrm{~mm}$, and $9 \mathrm{~mm}$ ) of CEC group although there was no significant difference between them. These results may be due to the CM of HyFlex EDM file that can be pre-bent to follow the anatomy of the canal which was considered to be highly flexible and can be tailored to the original shape of the canal, in addition to the rectangular cross section of HyFlex EDM, which may provide a better centralization of the rotary file in the curved canal, this comes in agreement with Ozyurek and Yılmaz [37].

Finally, while the available evidence suggests that the most important factor impacting the survival of root-filled teeth is the amount of remaining dentin [38], [39], [40], [41] which highlights the significance of conserving dentin as a critical factor responsible for the fate of root-filled teeth, endodontic access cavity designs should be subjected to assessment of associated benefits and risks, as the elimination of intracanal bacteria to levels acceptable with periradicular tissue healing is paramount for root canal treatment success, the effect of minimally invasive endodontic approaches on the disinfection of root canals as well as the fracture resistance of endodontically treated teeth should be further assessed and considered before adopting this new design.

\section{Conclusion}

Based on the results of this in vitro study, HyFlex EDM single file performed similarly in CECs and TECs with regard to centering ability, while for transportation CECs negatively influenced the original canal anatomy.

\section{References}

1. Silva EJ, Rover G, Belladonna FG, de-Deus G, Teixeira CS, Fidalgo TK. Impact of contracted endodontic cavities on fracture resistance of endodontically treated teeth: A systematic review of in vitro studies. Clin Oral Investig. 2018;22(1):109-18. https:// doi.org/10.1007/s00784-017-2268-y

PMid:29101548

2. Yuan K, Niu C, Xie Q, Jiang W, Gao L, Huang Z, et al. Comparative evaluation of the impact of minimally invasive preparation vs. conventional straight-line preparation on tooth biomechanics: A finite element analysis. Eur J Oral Sci. 2016;124(6):591-6. https://doi.org/10.1111/eos.12303 PMid:27704709

3. Lin C, Lin D, He W. Impacts of 3 different endodontic access cavity designs on dentin removal and point of entry in 3-dimensional digital models. J Endod. 2020;46(4):524-30. https://doi.org/10.1016/j.joen.2020.01.002 PMid:32115250

4. Hassan R, Roshdy N, Issa N. Comparison of canal transportation and centering ability of Xp Shaper, WaveOne and Oneshape: A cone beam computed tomography study of curved root canals. Acta Odontol Latinoam. 2018;31(1):67-74.

PMid:30056469

5. Hargreaves K, Cohen S. Cohen's Pathways of the Pulp. 10th ed. Amsterdam: Mosby; 2010.

6. Elnaghy AM, Elsaka SE. Evaluation of root canal transportation, centering ratio, and remaining dentin thickness associated with ProTaper next instruments with and without glide path. J Endod. 2014;40(12):2053-6. https://doi.org/10.1016/j.joen.2014.09.001 PMid:25301350

7. Capar ID, Ertas H, Ok E, Arslan H, Ertas ET. Comparative study of different novel nickel-titanium rotary systems for root canal preparation in severely curved root canals. J Endod. 2014;40(6):852-6. https://doi.org/10.1016/j.joen.2013.10.010 PMid:24862716

8. da Frota MF, Filho IB, Berbert FL. Cleaning capacity promoted by motor driven or manual instrumentation using ProTaper Universal system: Histological analysis. J Conserv Dent. 2013;16(1):79-82. https://doi.org/10.4103/0972-0707.105305 PMid:23349583

9. Lammertyn PA. Furcation groove of maxillary first premolar thickness and dentin structures. J Endod. 2009;35(6):814-7. https://doi.org/10.1016/j.joen.2009.03.012 PMid:19482177

10. Kishen A. Mechanisms and risk factors for fracture predilection in endodontically treated teeth. Endod Top. 2006;13:57-83. https://doi.org/10.1111/j.1601-1546.2006.00201.x

11. Elnaghy AM, Elsaka SE. Shaping ability of ProTaper gold and ProTaper universal files by using cone-beam computed tomography. Indian J Dent Res. 2016;27(1):37-41. https://doi. org/10.4103/0970-9290.179812 PMid:27054859

12. Krishan $R$, Paqué $F$, Ossareh $A$, Kishen $A$, Dao $T$, Friedman $S$, et al. Impacts of conservative endodontic cavity on root canal instrumentation efficacy and resistance to fracture assessed in incisors, premolars, and molars. J Endod. 2014;40(8):1160-6. https://doi.org/10.1016/j.joen.2013.12.012 PMid:25069925

13. Eaton JA, Clement DJ, Lloyd A, Marchesan MA. Microcomputed tomographic evaluation of the influence of root canal system landmarks on access outline forms and canal curvatures in mandibular molars. J Endod. 2015;41(11):1888-91. https:// doi.org/10.1016/j.joen.2015.08.013 


\section{PMid:26433857}

14. Schneider SW. A comparison of canal preparations in straight and curved root canals. Oral Surg Oral Med Oral Pathol. 1971;32(2):271-5. https://doi. org/10.1016/0030-4220(71)90230-1 PMid:5284110

15. Fayyad DM, Sabet NE, El-Said Mahmoud EH. Computed tomographic evaluation of the apical shaping ability of hero shaper and Revo-S. Quintessence Int. 2012;6(2):119-24.

16. Patel S, Rhodes J. A practical guide to endodontic access cavity preparation in molar teeth. Br Dent J. 2007;203(3):133-40. https://doi.org/10.1038/bdj.2007.682

PMid:17694021

17. Goerig AC, Michelich RJ, Schultz HH. Instrumentation of root canals in molar using the step-down technique. J Endod. 1982;8(12):550-4. https://doi.org/10.1016/ s0099-2399(82)80015-0

PMid:6962274

18. Clark D, Khademi J. Modern molar endodontic access and directed dentin conservation. Dent Clin North Am. 2010;54(2):249-73. https://doi.org/10.1016/j.cden.2010.01.001 PMid:20433977

19. Moore B, Verdelis K, Kishen A, Dao T, Friedman S. Impacts of contracted endodontic cavities on instrumentation efficacy and biomechanical responses in maxillary molars. J Endod. 2016;42(12):1779-83. https://doi.org/10.1016/j. joen.2016.08.028

PMid:27871481

20. Gambill JM, Alder M, del Rio CE. Comparison of nickeltitanium and stainless steel hand-file instrumentation using computed tomography. J Endod. 1996;22(7):369-75. https://doi. org/10.1016/s0099-2399(96)80221-4

PMid:8935064

21. Cicchetti DV. Guidelines, criteria, and rules of thumb for evaluating normed and standardized assessment instruments in psychology. Psychol Assess. 1994;6(4):284-90. https://doi. org/10.1037/1040-3590.6.4.284

22. Plotino G, Grande NM, Isufi A, loppolo P, Pedulla E, Bedini R, et al. Fracture strength of endodontically treated teeth with different access cavity designs. J Endod. 2017;43(6):995-1000. https://doi.org/10.1016/j.joen.2017.01.022

PMid:28416305

23. Gutmann JL. Minimally invasive dentistry (Endodontics). J Conserv Dent. 2013;16(4):282-3. https://doi. org/10.4103/0972-0707.114342

PMid:23956526

24. Gutmann JL. The dentin-root complex: Anatomic and biologic consideration in restoring endodontically treated teeth. J Prosthet Dent. 1992;67(4):458-66. https://doi. org/10.1016/0022-3913(92)90073-j

PMid:1507126

25. Rhodes JS, Pitt Ford TR, Lynch JA, Liepins PJ, Curtis RV. Microcomputed tomography: A new tool for experimental endodontology. Int Endod J. 1999;32(3):165-70. PMid:10530203

26. Gluskin AH, Brown DC, Buchanan LS. A reconstructed computerized tomographic comparison of NiTi rotary GT files versus traditional instruments in canals shaped by novice operators. Int Endod J. 2001;34(6):476-84. https://doi. org/10.1046/j.1365-2591.2001.00422.x

PMid:11556516

27. Uyanik M, Cehreli Z, Mocan B, Dagli F. Comparative evaluation of three nickel-titanium instrumentation systems in human teeth using computed tomography. J Endod. 2006;32(7):668-71. https://doi.org/10.1016/j.joen.2005.12.015

PMid:16793477

28. Saber S, Abu El Sadat S. Effect of altering the reciprocation range on the fatigue life and the shaping ability of WaveOne nickel-titanium instruments. J Endod. 2013;39(5):685-8. https:// doi.org/10.1016/j.joen.2012.12.007

PMid:23611391

29. Pawar AM, Thakur B, Metzger Z, Kfir A, Pawar M. The efficacy of the self-adjusting file versus WaveOne in removal of root filling residue that remains in oval canals after the use of ProTaper retreatment files: A cone-beam computed tomography study. J Conserv Dent. 2016;19(1):72-6. https://doi. org/10.4103/0972-0707.173204

PMid:26957798

30. Swain MV, Xue J. State of the art of micro-CT applications in dental research. Int J Oral Sci. 2009;1(4):177-88.

PMid:20690421

31. Bürklein S, Donnermeyer D, Hentschel TJ, Schäfer E. Shaping ability and debris extrusion of new rotary nickel-titanium root canal instruments. Materials. 2021;14(5):1063. https://doi. org/10.3390/ma14051063

PMid:33668333

32. Arıcan-Öztürk B, AtavAteş A, Fişekçioğlu E. Cone-beam computed tomographic analysis of shaping ability of XP-endo shaper and ProTaper next in large root canals. J Endod. 2020;46(3):437-43. https://doi.org/10.1016/j.joen.2019.11.014 PMid:31911004

33. Domark JD, Hatton JF, Benison RP, Hildebolt FC. An ex vivo comparison of digital radiography and cone beam and micro computed tomography in the detection of the number of canals in the mesiobuccal roots of maxillary molars. J Endod. 2013;39(7):7901-5. https://doi.org/10.1016/j. joen.2013.01.010

PMid:23791260

34. Peters OA. Current challenges and concepts in the preparation of root canal systems: A review. J Endod. 2004;30(8):559-67. PMid:15273636

35. Alovisi M, Pasqualini D, Musso E, Bobbio E, Giuliano C, Mancino D, et al. Influence of contracted endodontic access on root canal geometry: An in vitro study. J Endod. 2018;44(4):61420. https://doi.org/10.1016/j.joen.2017.11.010 PMid:29336881

36. Rover G, Belladonna FG, Bortoluzzi EA, de-Deus G, Silva EJ, Teixeira CS. Influence of access cavity design on root canal detection, instrumentation efficacy, and fracture resistance assessed in maxillary molars. J Endod. 2017;43(10):1657-62. https://doi.org/10.1016/j.joen.2017.05.006 PMid:28739013

37. Ozyurek T, Yılmaz G. Shaping ability of reciproc, WaveOne GOLD, and HyFlex EDM single-file systems in simulated s-shaped canals. J Endod. 2017;43(5):805-9. https://doi. org/10.1016/j.joen.2016.12.010 PMid:28292599

38. Linn J, Messer HH. Effect of restorative procedures on the strength of endodontically treated molars. J Endod. 1994;20(10):479-85. https://doi.org/10.1016/s0099-2399(06)80043-9 PMid:7714419

39. Ng YL, Mann V, Gulabivala K. A prospective study of the factors affecting outcomes of nonsurgical root canal treatment: Part 1: Periapical health. Int Endod J. 2011;44(7):583-609. https://doi. org/10.1111/j.1365-2591.2011.01872.x PMid:21366626

40. Ng YL, Mann V, Gulabivala K. Tooth survival following non-surgical root canal treatment: A systematic review of 
the literature. Int Endod J. 2010;43(3):171-89. https://doi. org/10.1111/j.1365-2591.2009.01671.x

PMid:20158529

41. Caplan DJ, Cai J, Yin G, White BA. Root canal filled versus non-root canal filled teeth: A retrospective comparison of survival times. J Public Health Dent. 2005;65(2):90-6. https:// doi.org/10.1111/j.1752-7325.2005.tb02792.x

PMid:15929546 